\title{
"NOVOS SINTOMAS" E DECLÍNIO DA FUNÇÃO PATERNA: UM EXAME CRÍTICO DA QUESTÃO
}

Rosane Zétola Lustoza, Mauricio José d'Escragnolle Cardoso e Roberto Calazans

Rosane Zétola Lustoza

Doutora em Teoria Psicanalítica

(UFRJ); professora adjunta da

Universidade

Federal do Paraná

(UFPR).

Mauricio José

d'Escragnolle Cardoso

Doutor em Ciências

da Linguagem,

Université Paris

$\mathrm{X}$, Nanterre;

professor adjunto

da Universidade

Federal do Paraná

(UFPR).

Roberto Calazans

Doutor em Teoria

Psicanalítica

(UFRJ); professor

associado da

Universidade

Federal de São

João del Rei

(UFSJ); bolsista de produtividade em pesquisa nível 2

CNPq.
RESUMO: Partindo da perspectiva lacaniana, examina-se a relação entre declínio da função paterna e "novos sintomas". Critica-se a assimilação entre declínio da função paterna e declínio do Nome-do-pai. Investiga-se o termo "novos sintomas", demonstrando seu caráter contraditório. Conclui-se que a decadência da Lei social é compatível com a inscrição do Nome-do-pai; e que tal declínio engendrou novas patologias, mas que não são assimiláveis a sintomas. Palavras-chave: Novos sintomas, Nome-do-pai, Lei, Outro.

ABSTRACT: "New symptoms" and paternal function decline: a critical examination of the question. From the Lacanian perspective, it explores the relationship between the decline of the paternal function and the "new symptoms". It criticizes the assimilation between paternal function decline and the decline of the Nameof-the-Father. It examines the term "new symptoms", showing its contradictory character. It concludes that the decline of social law is compatible with the inscription of the Name-of-the-Father, and that such a decline engendered new pathologies, but these are not assimilable to symptoms.

Keywords: New symptoms, Name-of-the-Father, Law, Other. 


\section{APRESENTAÇÃO DO PROBLEMA}

$\mathrm{Na}$ época contemporânea assiste-se a uma decadência dos grandes referenciais de avaliação que cimentavam o mundo social. Se antigamente as escolhas dos sujeitos eram norteadas pelos sólidos códigos de interpretação ofertados pela tradição, pela autoridade ou pela religião, hoje se observa um desmoronamento das balizas que conferiam coesão à sociedade. O homem se vê então sem uma grade de leitura que lhe permita decifrar os acontecimentos de seu mundo. Bauman (2001) chama de 'modernidade líquida' esse tempo em que qualquer convicção assumida pelo sujeito torna-se transitória, frágil, prestes a se volatilizar e dar lugar a outra.

Nesse novo contexto social, qualquer um que pretenda assumir o lugar da exceção é, em pouco tempo, rechaçado como um impostor ridículo. A própria Lei social é considerada um artifício, uma ficção cultural, que os sujeitos encaram com desconfiança e rejeitam como um mero semblante.

Na época de Freud, a moral da sociedade repressiva promovia a interdição do gozo; já hoje, em que está proibido proibir, em que a barreira ao gozo parece ter sido removida, os sujeitos parecem concluir que tudo é permitido. O filósofo Gilles Lipovetsky (2005) chama nossa sociedade de pós-moralista, na medida em que colocaria em jogo um crepúsculo do dever. Já Zizek (2008) sublinha não exatamente uma ausência de dever, mas uma nova qualidade de dever, em que o gozar torna-se uma obrigação moral.

Esse discurso que fomenta a busca de gozo tem sérias repercussões clínicas. Assiste-se hoje à proliferação de patologias em que os atos parecem substituir a palavra. O fato de os atos predominarem sobre as palavras sinaliza uma hegemonia de respostas subjetivas pela via do gozo; daí muito do que se encontra sob a rubrica "novos sintomas" referir-se sobretudo a uma clínica das impulsões: bulimia, anorexia, novos tipos de adicções, hiperatividade, etc.

Que os novos sintomas encontram-se ligados ao declínio da função paterna parece evidente. Contudo, um exame mais minucioso revela quão pouco evidente é o sentido dos termos cuja ligação é afirmada.

Comecemos pelo termo "função paterna”. Afirmar seu declínio é legítimo, se com isso nos limitamos a constatar a dissolução dos grandes códigos de conduta que governavam a sociedade. Faz-se, porém, uma extrapolação abusiva quando se pretende tratar o dito declínio como uma derrocada do Nome-do-pai (como operador psíquico). Como nem sempre nos textos de psicanalistas essa discriminação é feita, muitos acabam assimilando de modo equívoco a decadência da lei simbólica a um apagamento do Nome-do-pai. Isso leva a certas confusões, como afirmar que estaria em cena uma nova subjetividade, a qual teria desalojado o velho sujeito neurótico freudiano de seu antigo posto; ou afirmar que a sociedade tornou-se majoritariamente psicótica ou perversa. 
Já o termo "novos sintomas" nos parece problemático por outras razões. Trata-se de um conjunto de fenômenos muito heterogêneos, a ponto de se poder indagar se é uma categoria conceitual cujos contornos podem ser precisados ou se constitui, ao contrário, uma noção confusa. Sua obscuridade não a torna, apesar disso, uma categoria pouco utilizada. Por surgir com frequência na cena do debate analítico, faz-se mister pensar seu estatuto conceitual.

A fim de investigar a legitimidade dessa tese, nosso percurso será inicialmente separar Nome-do-pai e Lei social. Num segundo momento, investigaremos o sentido do termo 'novos sintomas', para só então estabelecer uma relação entre Nome-do-pai, lei social e novos sintomas.

\section{NOME-DO-PAI E LEI SOCIAL}

O filme Entre os muros da escola, de Laurent Cantet (2008), é verdadeiramente emblemático desses tempos líquidos. Assistimos ali, reproduzido de forma microscópica, um problema que afeta não apenas a escola, mas, em larga escala, toda a sociedade. O professor parece ser tratado o tempo inteiro por seus alunos como uma fraude, alguém que não tem a menor legitimidade para ocupar a posição que ocupa e cuja palavra não exerce mais qualquer eficácia. Os estudantes contestam qualquer pretensão à assimetria de lugares: todos são iguais, não há por que obedecer a algo que não se compreende, pois a obediência por pura transferência é recusada. O filme torna-se um diagnóstico dos nossos tempos na medida em que, ao retratar a dificuldade pessoal daquele professor específico, o diretor atinge uma verdade geral, pois, hoje, qualquer um que busque reivindicar para si o lugar da exceção é violentamente rejeitado como um blefador patético, que oculta sua impotência sob o disfarce da Lei. Parece que todos nós sabemos, de forma selvagem, algo que só deveria emergir ao fim de uma análise: o grande Outro não existe.

Porém, é preciso perguntar, como faz Zupancic (2007): se é verdade que todos nós sabemos que o Outro não existe, será que efetivamente agimos como se soubéssemos disso? Esta pergunta é importante, pois é possível que, no final das contas, descubramos, para nossa própria surpresa, que por trás da aparente destruição das velhas crenças, subsiste pelo menos uma: a crença inconsciente na existência de Deus (LACAN, 1969-70/1992).

Conforme Zupancic (2007), o que de hábito se descreve como a inexistência do Outro é uma tese que merece maiores precisões. Pois o que houve de fato foi uma descrença generalizada na possibilidade de que um pequeno outro qualquer possa ocupar o lugar do Outro. Pais, professores, líderes políticos, enfim, todos os outros suscetíveis de ocupar um lugar especial nas séries psíquicas inconscientes, passaram a ser alvo de uma crítica que não deixa ninguém de fora. O que existe é uma grande 
dificuldade de acreditar que um pequeno outro qualquer mereça ser catapultado ao lugar de grande Outro.

\begin{abstract}
“Em outras palavras, o que é abandonada é a possibilidade de um laço ou de um curto-circuito entre o pequeno e o grande Outro, a possibilidade de acreditar que o 'pequeno outro' possa ser o próprio modo de existência do grande Outro. Nenhuma pessoa concreta (pai, professor, presidente) é verdadeiramente a instância do Outro, porque eles são apenas humanos, inconsistentes, quando não completamente fracos e patéticos." (ZUPANCIC, 2007, p.6)
\end{abstract}

Mas, que não se pense que essa operação é inócua. Na medida em que ninguém está autorizado a se confundir com o Outro, entra em jogo também uma extraordinária operação de salvamento, na qual o lugar vazio nunca é questionado. O saldo dessa manobra é que o grande Outro permanece preservado como um lugar vazio. O lugar do Outro fica fora de qualquer mácula, mantido à distância do mundo; ele pode continuar "inteiro, não barrado e onisciente em sua ignorância, na medida em que não está ativo, que não opera em nenhum pequeno outro (o que significa dizer que ele está a priori isento de qualquer responsabilidade nesse nível)" (ZUPANCIC, 2007, p.7). É como se a não existência do Outro na realidade não o impedisse de continuar a exercer sua eficácia: afinal, nada mais indestrutível do que aquilo que não existe!

Ou seja, se por um lado nenhum discurso consegue ser suficientemente sedutor ou persuasivo para demover o sujeito de sua descrença, resta ainda viva nele uma crença: a de que o Pai ausente... faz falta! O lugar vazio do Pai não é sem consequências: nos casos mais extremos, ele pode gerar tanto o apelo desesperado quanto a desistência resignada. Isso gera alguns paradoxos, tais como o apontado por Zizek (2009), em que o sujeito se ressente pelo fato de o Outro não existir e o culpa por isso. Conforme Rocha (2010) ilustra à perfeição: “Essa postura evoca a fala do protagonista de Fim de caso, de Graham Greene: 'eu o odeio, Deus, como se você realmente existisse” (p.193). O que é uma nova versão da velha fórmula freudiana de que o Pai morto é ainda mais forte do que vivo.

Note-se, portanto, que a inscrição do Nome-do-pai é compatível com um ambiente de descrença em figuras de autoridade. Isso não significa que a instalação do Nome-do-pai necessariamente ocorrerá; a ausência desse processo é nomeada por Lacan de foraclusão e resulta numa psicose. O importante a frisar aqui é que a falência da autoridade não possui uma relação direta de causalidade com a psicose; a dita falência não autoriza qualquer previsão acerca da escolha da estrutura pelo sujeito. Como afirma Maleval (2007), “o declínio da autoridade não é o declínio do Nome-do-pai: as modificações da lei social não têm qualquer efeito sobre a lei do significante" (p.155). 
Apesar de não decidirem diretamente a estrutura, as mutações sociais sem dúvida impactam o modo como os fenômenos se apresentam nas diferentes estruturas. O enfraquecimento da adesão coletiva aos ideais leva o sujeito a uma errância e precariedade maiores, o que explica a prevalência de certas síndromes no momento atual (MALEVAL, 2007). Um exemplo são os recentes debates sobre o conceito de psicose ordinária (MILLER et al., 2005), cujas características se afastam do quadro tradicional daquela patologia: em vez de delírios e alucinações, passam a ter lugar fenômenos muito mais difusos e sutis. A neurose parece também se manifestar sob a forma dos "novos sintomas”. Apesar da nova roupagem, o importante a frisar aqui é que as mudanças ocorridas não concernem à lógica das estruturas subjetivas. "Mutações dos sintomas, consequentemente, e não das estruturas subjetivas” (MALEVAL, 2007, p.155).

\section{NOVOS SINTOMAS}

Costuma-se reunir sob a rubrica de "novos sintomas" uma lista heteróclita de fenômenos: depressão, transtorno de pânico, bulimia, anorexia, novas adicções, etc. Tal fato por si só já deve nos advertir que lidamos com fenômenos cujas classificações conceituais talvez sejam muito diferentes entre si. Ao longo de nossa exposição, pretende-se demonstrar que as novas patologias não formam uma categoria conceitual bem delimitada, mas uma noção confusa, que mescla elementos cuja natureza é distinta.

Aceitemos por ora os termos em que o problema é colocado. O ponto de partida clínico é que se assiste hoje a uma ascensão de patologias cujo ponto em comum seria sua profunda repelência à palavra, o que as tornariam impermeáveis à interpretação psicanalítica tradicional. O paciente parece imerso num sofrimento silencioso. O paradigma comumente tomado é o da toxicomania, na qual fica clara uma busca de gozo tão poderosa que parece suspender o poder simbólico da palavra.

A primeira interrogação a ser feita acerca dos "novos sintomas" é saber se, de fato, correspondem à definição freudo-lacaniana deste conceito. Em psicanálise, o sintoma (symptôme) é uma formação do inconsciente que tem estrutura de linguagem. Ele é o resultado final de um processo de deslocamentos e condensações, o que permite por isso mesmo uma decifração a posteriori do seu sentido. O problema com esses "novos sintomas" é justamente que não se deixam abordar pela manobra interpretativa clássica, em que um sentido latente pode surgir para além do sentido manifesto.

Num texto bastante elucidativo, Recalcati (2004) compara as operações exigidas na clínica clássica e na clínica contemporânea. Na clínica clássica, o sujeito chega com uma demanda de cura, de livrar-se de algo insuportável. A manobra 
analítica seria aqui dupla: tentar tanto uma transformação heurística quanto ética da demanda. Heurística, na medida em que a pré-interpretação que o sujeito faz de seu sintoma deve ser substituída pela busca de uma verdade inconsciente. Essa transformação heurística — da vontade de se curar em vontade de saber - se faz acompanhar também por uma mutação ética. "A transformação ética da demanda consiste em indicar ao sujeito a parte que ele tem na fabricação e na preservação de sua condição de sofrimento. Portanto, em fazer trabalhar no sujeito a dimensão ética da culpa” (RECALCATI, p.5).

Na clínica contemporânea, essa dupla operação não parece possível. Pois o que está problematizado é a própria dimensão da demanda. Miller \& Laurent (2005) chamam tal demanda de convulsiva, pois visa obter o objeto de gozo de forma direta e ininterrupta. É como se houvesse uma busca imediata pela satisfação, num curto-circuito em que o sujeito se poupa de se dirigir ao grande Outro simbólico na busca de gozo. Busca-se desse modo uma satisfação que não passa pelo Outro e sim pelo próprio corpo, e que constituiria uma forma de autoerotismo.

Para circunscrever a dificuldade que uma demanda convulsiva coloca para o tratamento, recordemos que a demanda, em sua acepção clássica, sempre se dirige ao Outro simbólico. Ao demandar algo ao Outro, o sujeito experimenta o retorno de uma mensagem, o que o leva a ressignificar sua posição inicial. Ao mesmo tempo, uma vez que a demanda está fundamentalmente centrada na resposta do Outro, ela obriga o sujeito a sustentar um intervalo entre o pedido e a resposta, a suportar um adiamento da satisfação. Acontece que o discurso contemporâneo incentiva uma demanda que não se dirige ao Outro simbólico, pois o objeto de gozo está implicado de forma mais imediata. O sujeito tem a esperança de encontrar o objeto sob uma forma mais direta, sem passar pelas intempéries e acidentes de percurso que experimenta quando tenta encontrar a satisfação pelo viés do desejo do Outro.

Ressalte-se neste ponto a importante influência do discurso capitalista na proliferação dos ditos "novos sintomas”. Não exatamente porque o capitalismo seja deles a causa, mas porque convida o sujeito a negar a castração pela via do objeto de consumo, oferecendo-lhe sem cessar uma série de artefatos tecnológicos destinados a tamponar a falta — cirurgias estéticas, medicamentos psiquiátricos, drogas para disfunção erétil, etc. No capitalismo contemporâneo, a atividade de consumo (ou seja, a fruição de um bem) torna-se mais valorizada do que a atividade produtiva (isto é, a construção de um bem, o trabalho necessário para transformar algo em mercadoria) (BAUMAN, 2008). Em termos psicanalíticos, diríamos que o gozo torna-se mais importante que o desejo (LUSTOZA, 2009). Por isso diz-se que no discurso capitalista houve uma ascensão ao zênite do objeto a. Ao contrário dos outros discursos, cuja função seria refrear o gozo, o discurso capitalista é o único dentre eles cuja função seria fomentar o gozo. 
Uma coisa é o discurso; outra, bem diferente, são as reações subjetivas a este discurso. Dessa forma, os "novos sintomas" devem ser situados como respostas subjetivas ao discurso que incita o gozo. A pergunta a ser feita aqui é: seriam tais respostas assimiláveis a sintomas? Nossa conclusão é um tanto paradoxal: pois o que os "novos sintomas" têm em comum é justamente o fato de... não serem sintomas! Pelo menos não no sentido freudo-lacaniano do conceito. Se apelarmos para o famoso quadro de respostas subjetivas, exposto por Lacan (1962-63/2005) no Seminário 10, teríamos que classificar os "novos sintomas" mais próximos do acting out, da passagem ao ato, até mesmo da inibição, que do sintoma.

Comparemos:

a) O acting out seria um ato impulsivo em que o sujeito visa sair de um impasse simbólico de forma desesperada, mostrando algo ao Outro. Tal ato pressupõe uma demanda-demanda que não é posta em palavras, mas que antes mostra alguma coisa ao Outro. Na verdade, mesmo quando o acting se dá mediante o uso de palavras, estas visam expor à luz do dia alguma coisa que em geral se encontra velada, oculta.

O que o acting mostra? Para responder a isso, voltemos ao comentário de Lacan (1962-63/2005) sobre o famoso caso do Homem dos Miolos Frescos, de E. Kris: o analista prova de maneira irrefutável que seu paciente, que se apresentara como um plagiador, não havia copiado o trabalho de um rival. Impedido de ocupar o lugar de ladrão de ideias, o paciente logo em seguida comete um acting out: ao sair da sessão, passa num restaurante exótico e consome miolos frescos, contando tal fato ao analista na sessão seguinte.

O efeito da interpretação de Kris foi deixar o paciente sem lugar, como se toda a verdade do sujeito tivesse sido dita, sem espaço para qualquer zona de sombra. Por isso o acting tem sempre a função de marcar um 'isso não é tudo': resta algo por dizer. "Com os miolos frescos, o paciente simplesmente faz um sinal para Kris: tudo o que o senhor diz é verdade, mas simplesmente não toca na questão; restam os miolos frescos. Para mostrá-lo ao senhor, vou comê-los ao sair, para lhe mostrar na próxima sessão” (LACAN, 1962-63/2005, p.139). Se esse resto não pode ser dito, a saída é que ele seja visto, visibilizado, exposto. "O essencial do que é mostrado é esse resto, é sua queda, é o que sobra nessa estória" (p.139). O objeto no acting deixa seu estado habitual de causa ausente do desejo e sobe à cena sob a forma de uma exibição de gozo.

A função da mostração no acting fica patente num caso clínico relatado por Alberti (1998), em que o paciente consumia e negociava drogas de maneira ostensiva no playground do próprio prédio do pai. Um pai que, muito absorvido por sua vida profissional, com frequência ignorava o filho. A analista interpreta a mostração no playground como um "apelo à função paterna, em que a droga é o instrumento de transgressão para fazer existir a lei” (p.127). 
Em que diferem acting e sintoma? Lacan (1962-63/2005) ensina que o acting clama por interpretação; já o sintoma, apesar de interpretável, não é essencialmente um apelo à interpretação.

“O sintoma não é como o acting out, que pede interpretação, pois (...) o que a análise descobre no sintoma é que ele não é um apelo ao Outro, não é aquilo que mostra ao Outro. O sintoma, por natureza, é gozo, não se esqueçam disso, gozo encoberto, sem dúvida (...), não precisa de vocês como o acting out, ele se basta." (LACAN, 1962-63/2005, p.140)

Ou seja, o sintoma não mostra nada, o gozo está nele encoberto. Eis aqui uma diferença crucial: no sintoma há gozo encoberto, ao passo que no acting há mostração de gozo. Pode-se perguntar: se algumas das novas patologias são na verdade actings, por que razão seriam mais resistentes à manobra da interpretação que os sintomas? Aceitando a observação dos clínicos de que as patologias do ato são menos favoráveis à interpretação, e se o acting é uma dessas patologias, por que razão seria mais resistente à intervenção, se a essência do acting é ser justo um apelo - coisa que um sintoma não é fundamentalmente?

Desde Freud (1914/1969), sabe-se que a elaboração e a verbalização envolvem uma suspensão do ato motor. Na análise, um impulso que se dirigiria à esfera motora pode ser canalizado para a esfera psíquica, o que significa que o ato de pensamento envolve uma colocação entre parênteses do ato motor. De modo inverso, quando a atuação prevalece, torna-se mais complicada a abertura à intervenção analítica e à mobilização do processo de pensar. Além disso, como no acting existe invariavelmente um destinatário do ato, o sujeito não se implica de forma direta naquilo que faz. Acrescentem-se, ainda, os efeitos disruptivos e desorganizadores que a subida à cena do objeto a provoca (MILLER, 2007); o que pode de fato trazer dificuldades adicionais de manejo para o tratamento.

b) Passagem ao ato - A passagem ao ato envolve justamente a saída do sujeito da cena. Não havendo mais lugar para si numa configuração simbólica determinada, o sujeito então se evade da cena. Assim, a passagem ao ato é o oposto do acting: enquanto no acting o sujeito se esforça por restituir um lugar na cena do Outro, na passagem ao ato o sujeito sem lugar na cena se abandona à posição de resto. Por isso o sujeito na passagem ao ato não demanda mais nada ao Outro; ele não se endereça mais a ele, apenas se identifica ao resto que caiu da cena.

No momento da passagem ao ato, temos uma situação de fato pouco propícia a um tratamento, na medida em que precisamente a dimensão da demanda é abolida e não há, portanto, apelo dirigido ao Outro.

Tarrab (2005) conta o caso de uma paciente cuja única atividade é ficar o tempo inteiro na frente do computador. Apesar dos desesperados protestos da 
família, ela persiste em seu vício em Internet, querendo apenas permanecer só, sem que ninguém a incomode. Ela não apela, nada demanda — isso porque na passagem ao ato o sujeito não age para inquietar o pai, a família, ou alguém específico (HARARI, 2008), ele simplesmente se demite da ficção simbólica, saindo de cena.

Nesse caso, Tarrab afirma ser impossível retirar a garota de sua obstinada indiferença pela via da decifração do sentido. A dificuldade do tratamento repousa aí, e isso o afasta da operação psicanalítica clássica.

c) Inibição — A inibição não envolve a execução de um ato, mas sua ausência. Ela é a restrição de uma função do Eu, tendo como finalidade evitar um conflito. Tal conflito surgiria caso fosse realizada certa atividade, ligada àquela função (FREUD, 1926 [1925]/2006).

Não seria o caso de algumas dessas novas patologias poderem ser classificadas como inibições? Com todo cuidado de não fazer generalizações ambiciosas, podem-se apontar, por exemplo, alguns casos de depressão como formas de inibição, em que o sujeito renuncia ao desejo por temer que isso reative o conflito e as terríveis censuras superegoicas.

A dificuldade clínica com a inibição é que ela é um momento de parada no tratamento: como é feita para impedir a emergência do conflito, este fica impossibilitado de se articular, ainda que de modo simbólico. Enquanto a inibição evita o surgimento do conflito, o sintoma supõe um conflito já instalado. Por isso é preciso que a inibição se transforme em sintoma para que o tratamento possa avançar.

Do que foi aqui exposto conclui-se que o traço em comum entre esses "novos sintomas" é o de não serem sintomas — pelo menos não no sentido freudiano de mensagem latente.

Pode-se usar a expressão de forma legítima caso a empreguemos no sentido mais amplo de sinthoma. É o que faz, por exemplo, Tarrab (2005) na seguinte passagem:

"a toxicomania, a bulimia, a anorexia, os ataques de pânico e tudo o mais que colocarmos nesse saco estão muito próximos do que Lacan chama a operação selvagem do sintoma, e vão na contramão da vertente simbólica do sintoma como mensagem. É o sintoma que não pede nada, que é fixação de gozo.” (TARRAB, 2005, p.3)

Este uso é importante e pode ser interessante, dependendo do nível de análise em que nos posicionamos. Contudo, acreditamos na necessidade de abandonar o nível da generalidade quando falarmos de respostas subjetivas específicas, a fim de podermos ter uma ideia mais adequada da riqueza das contribuições de Lacan para o campo. 


\section{CONCLUSÃO}

Escuta-se muito hoje que as patologias atuais impõem desafios e dificuldades para a teoria e a técnica psicanalítica. O que tentamos aqui defender foi a ideia de que as categorias tradicionais da psicanálise não foram ultrapassadas ou colocadas em xeque pelas patologias contemporâneas, pois a psicanálise tem, sim, instrumentos conceituais para pensá-las. Muitos desses fenômenos novos não são de fato redutíveis à definição tradicional do sintoma, pois seriam na verdade classificáveis como acting out, passagem ao ato e inibições. Temos razões para supor inclusive que essa lista não é exaustiva, pois no próprio Seminário 10, Lacan (1962-63/2005) elenca uma série de outras respostas subjetivas (impedimento, embaraço, efusão, etc.), cujo potencial ainda foi pouco explorado no campo analítico e que poderiam também servir como ferramentas conceituais para pensar a clínica contemporânea.

No entanto, devemos fazer justiça à observação, comum na literatura sobre os "novos sintomas", de que estes são inabordáveis pela decifração. Procuramos assinalar as dificuldades de manejo que as ditas patologias do ato apresentam. A interpretação pelo sentido não costuma funcionar nesses casos por diferentes razões. No caso do acting, observou-se como a adoção pelo sujeito da via da descarga motora e não da verbalização introduz um fator complicador no tratamento. A passagem ao ato é ainda mais preocupante, por ser um ato que não demanda mais nada ao Outro. Se não há demanda, a própria condição mínima para se fazer uma análise é questionada. Já a inibição — que é mais propriamente situável como uma ausência de ato - é problemática por supor uma paralisia do desejo: o desejo não está deslocado como no sintoma, pois a própria expressão desse desejo foi ceifada.

Embora fuja ao escopo desse artigo discutir o tipo de intervenção apropriada nesses casos, por ora queremos apenas sinalizar que a psicanálise tem um arsenal teórico e técnico para pensar tais fenômenos. Devemos conter nossa ânsia por novidades e não ficarmos desorientados pelo que aparece como inédito. Se a nossa civilização parece incitar uma busca pelo gozo sem precedentes, é necessário voltar aos fundamentos da nossa teoria e lembrar que tal busca é sempre marcada por uma impossibilidade. Retomando aqui o argumento de Godino Cabas (2009), há uma impossibilidade de o gozo saturar completamente o desejo. O sinal dessa impossibilidade aparecerá sob a forma de um afeto, "uma circunstância na qual o sujeito do inconsciente se vê profundamente afetado. Ora por uma decepção ('não era isso'), ora por um estado de tédio" (p.236). Ou seja, transposto o umbral do princípio do prazer e iniciada a busca incessante de gozo, no caminho para ele há algo que atualiza o mal-estar e que indica que o gozo encontrado não é ainda suficiente. O excesso de gozo traz tédio ou decepção. 
Serão precisamente esses afetos (tédio, decepção, angústia) que podem possibilitar uma via de saída e de acesso a um desejo. Se o método analítico tem ainda alguma chance de curar, é por encontrar nesses afetos um ponto de apoio para a eficácia de intervenção.

Talvez seja pouco preciso dizer que tais afetos constituem um limite ao gozo. Um afeto não é exatamente um limite, uma vez que não leva de fato ao refreamento do gozo. Ele não representa um dique de contenção, tal como era a lei repressiva dos tempos freudianos. Mas ele é um limite num sentido mais largo, como um índice de que algo vai mal. Tampouco podemos dizer que tais afetos necessariamente suscitarão uma demanda. É essa a dificuldade dos "novos sintomas”, o não endereçamento ao Outro. Mas, insistimos, embora a presença de tais afetos não seja condição suficiente para a saída do gozo autista, representa sua condição necessária.

Um esclarecimento importante em relação ao diagnóstico: pensamos que os “novos sintomas" são fenômenos compatíveis em principio com as três estruturas clínicas. Por exemplo, a passagem ao ato ocorre tanto na psicose quanto na neurose ou na perversão. O que acontece é que os “novos sintomas” impõem uma dificuldade a mais na definição inicial do diagnóstico, levando o clínico a não conseguir classificar de imediato qual a estrutura clínica em jogo. Isso não equivale a uma abolição do diagnóstico estrutural, mas a admissão de que nem sempre é possível decidir com convicção a classificação do caso num dado momento.

A função das entrevistas preliminares ganha aqui uma justificativa adicional, pois será preciso que o analista se oponha às atuações e que suas intervenções visem promover um corte do excesso de gozo. Somente quando o “sintoma” está em perda de gozo é que o sujeito pode colocá-lo em jogo pela via da palavra. Os "novos sintomas" impõem, portanto, uma questão preliminar ao tratamento, por constituírem uma situação de urgência subjetiva. A urgência demanda do analista um manejo para que o sujeito seja colocado em condições de fazer análise e de aceder à regra fundamental. Que fique claro: assegurar que o sujeito tenha condições de respeitar minimamente o dispositivo da associação livre não significa que ele esteja em análise, mas é um passo prévio a isso, uma condição de possibilidade do tratamento.

O diagnóstico quase sempre só pode ser feito após se obter um apaziguamento da urgência. Isso significa que urgência é um fator que complica a emissão do diagnóstico diferencial. De qualquer forma, é importante frisar que os "novos sintomas" não são apanágio de um estrutura clínica específica. Eles não apenas não servem para fazer o diagnóstico diferencial como o dificultam.

Em relação à falência da autoridade simbólica, é importante frisar que tal falência está decerto articulada à proliferação das patologias do ato. O que se 
procurou demonstrar aqui é que o dito declínio não significa necessariamente declínio do Nome-do-pai. O Nome-do-pai poderá estar inscrito ou não, o que deve ser diagnosticado caso a caso.

Uma estrutura discursiva que incita ao gozo certamente terá impactos diferenciados sobre as estruturas clínicas - neurose, psicose e perversão. Deve-se aqui pensar de maneira estrutural: um fenômeno (por exemplo, uma passagem ao ato) até pode ter uma organização interna, mas seu sentido e função serão pensados a partir da sua articulação aos outros na lógica da estrutura. No exemplo da passagem ao ato, são diversos os recursos com os quais o sujeito conta para lidar com ela: estes recursos serão muito diferentes numa psicose (em que não há inscrição do Nome-do-pai) e na neurose (em que há inscrição).

Recebido em 5/3/2012. Aprovado em 11/6/2012.

\section{REFERÊNCIAS}

ALBERTI, S. (1998). “Adolescência e droga: um caso”, in BENTES, L. \& GOMES, R. F. (Orgs.). O brilho da infelicidade/Kalimeros. Rio de Janeiro: Contra Capa.

BAUMAN, Z. (2001) Modernidade líquida. Rio de Janeiro: Zahar. . (2008) Vida para consumo: a transformação das pessoas em mercadoria. Rio de Janeiro: Zahar.

CABAS, A. G. (2009) O sujeito na psicanálise de Freud a Lacan: da questão do sujeito ao sujeito em questão. Rio de Janeiro: Zahar

CANTET, L. (2008) Entre os muros da escola. São Paulo: Imovision.

FREUD, S. (2006) Edição standard brasileira das obras psicológicas completas de Sigmund Freud. Rio de Janeiro: Imago.

(1914) “Recordar, repetir e elaborar”, v.XII, p.159-171.

(1926 [1925]) “Inibições, sintomas e ansiedade”, v.XX, p.79-167.

HARARI, A. (2008) “Fundamentos da prática lacaniana: risco e corpo”. Tese de doutorado, Programa de pós-graduação em Psicologia Clínica, Instituto de Psicologia, Universidade de São Paulo.

LACAN, J. (1962-1963/2005). O seminário livro 10: A angústia. Rio de Janeiro: Zahar.

(1969-1970/1992). O seminário livro 17: O avesso da psicanálise. Rio de Janeiro: Zahar.

LIPOVETSKY, G. (2005) A sociedade pós-moralista: o crepúsculo do dever e a ética indolor dos novos tempos democráticos. Barueri: Manole.

LUSTOZA, R. (2009) O discurso capitalista de Marx a Lacan: algumas consequências para o laço social. Ágora, v.12, n.1, p.41-52, jan/jun.

MALEVAL, J. C. (2007) Foraclusão. Opção lacaniana, 50. São Paulo: Eolia, p.153-156. 
MILLER, J. A. (2007) La angustia lacaniana. Buenos Aires: Paidós. \& LAURENT, E. (2005) El Otro que no existe y sus comités de ética. Buenos Aires: Paidós. . et al. (2005). La psicosis ordinaria. Buenos Aires: Paidós.

RECALCATI, M. (2004). A questão preliminar na época do Outro que não existe. Latusa Digital, n. 7, ano 1, julho de 2004. Disponível em <http://www.latusa.com.br/pdf_latusa_digital_7_a2.pdf> Acesso em 23/11/2011.

ROCHA, S. P. V. (2010) Da morte de Deus à inexistência do Outro: reflexões sobre o niilismo contemporâneo. Ethica (Rio de Janeiro), v.17, n.2, p.190-199.

TARRAB, M. (2006) Produzir novos sintomas. Asephallus (Rio de Janeiro), ano 1, n.2, p.1-5, maio/out.

ZIZEK, S. (2008) A visão em paralaxe. São Paulo, Boitempo. (2009) O grande Outro não existe. Ethica (Rio de Janeiro), v.16, n.2, p.113-131.

ZUPANCIC, A. (2007) Freedom and cause. II Congresso Internacional de Filosofia da Psicanálise. São Carlos, SP, set.

Rosane Zétola Lustoza

rosanelustoza@yahoo.com.br

Mauricio José d`Escragnolle Cardoso

escragnolle@hotmail.com

Roberto Calazans

roberto.calazans@gmail.com 
